\title{
Strengthening Public and Private Sector Collaboration for the Dumagat in Sta. Ines, Tanay, Rizal: \\ Basis for A Four - Year IP Development Plan
}

\author{
Ana Christina M. dela Cruz
}

\begin{abstract}
Providing a framework for exploring governance systems that range from policy or program-based inter-governmental cooperation (Makati and Tanay) to place-based collaboration with non-governmental stakeholders to public-private partnerships (PPP).

Public-Private Partnership is geared towards financing, designing, implementing and operating facilities and services that are traditionally provided by the public sector. It embodies optimal risk allocation between the parties - minimizing cost while realizing project developmental objectives. Thus, the project is to be structured in such a way that the private sector gets a reasonable rate of return on its investment. This offers monetary and non-monetary advantages for the public sector. It addresses the limited funding resources for local IP development projects of the public sector, thereby allowing the allocation of public funds for other local priorities. The collaboration is geared for both sectors to gain improved efficiency and project implementation processes in delivering services to the IP community. Most importantly, it emphasizes Value for Money - focusing on reduced costs, better risk allocation, faster implementation, improved services and possible generation of additional revenue.

A Four - year Indigenous People (IP) Development Plan for the Dumagat community is a concrete response to the United Nations' 17 Sustainable Development Goals. Grounded in a vision that aims to transform our world - UN aspires to build a world free of poverty, hunger and disease, in which every woman and every girl enjoys full gender equality, where the environment is protected and where all people have access to quality education and decent work. The program is designed to create a sustainable community extension services for the IP community of Barangay Sta. Ines in Tanay, Rizal. The Dumagat community, characterized by lack of basic services, but open and willing to be organized to attain genuine and holistic development is the priority of the program. In the implementation, it will follow the different stages in community organizing to ensure the appropriateness of activities and training for community partners. Organizing the poorest of the poor can lead to empowerment. Also, it will allow them to become pro-active in ensuring the development of quality of life.
\end{abstract}

\section{Keywords:}

Governance; PPP; Indigenous People (IP); Development Plan 


\section{Introduction}

With 7,107 islands and three major administrative divisions, namely Luzon, Visayas and Mindanao, the Philippines is a home for numerous indigenous tribes who have managed to keep their cultural identity, despite the non-recognition and marginalization they are facing.

Although there are quite a number of indigenous tribes or ethnic groups in the country, they remain some of the most poor, least privileged, and impeded members of society. They mostly reside in the mountains, and hence were not affected by Spanish or American colonization, which is the primary reason they were able to retain their customs and traditions.

When the Sustainable Development Goals (SDGs), also known as the Global Goals, were adopted by all United Nations Member States in 2015 as a universal call to action to end poverty, protect the planet and ensure that all people enjoy peace and prosperity by 2030, countries have committed to fast-track progress for those furthest behind first. That is why the SDGs are designed to bring the world to several life-changing 'zeros', including zero poverty, hunger, and the like.

Through the pledge to "Leave No One Behind", everyone is needed to reach these ambitious targets. The creativity, knowhow, technology and financial resources from all of society is necessary to achieve the SDGs in every context. The 17 SDGs are integrated - that is, they recognize that action in one area will affect outcomes in others, and that development must balance social, economic and environmental sustainability.

The Philippine government supports the SDGs and had different programs suited to achieve the goals of sustainable development. It's "Ambisyon 2040" is a concrete answer to the attainment of these goals. SDGs and Ambisyon 2040 creates an impact to the lives of the Indigenous People, particularly the Dumagat community in Sta. Ines, Tanay, Rizal.

But even before the establishment of the SDGs, the Philippine Constitution, in recognition of this diversity and under the framework of national unity and development, mandates state recognition, protection, promotion, and fulfillment of the rights of Indigenous Peoples. Further, Republic Act 8371, also known as the "Indigenous Peoples Rights Act" (1997, IPRA), recognized the right of IPs to manage their ancestral domains; it has become the cornerstone of current national policy on IPs. 
With the collaborative efforts of the University of Makati (UMak) - College of Continuous, Advanced and Professional Studies (CCAPS) and the UMak - Community Extension Services (CES) Department, the City of Makati and the Municipality of Tanay had collaborative efforts to strengthen its commitment to help uplift the lives of some indigenous people in Tanay, Rizal, particularly the Dumagat.

The adoption of the Dumagat community in Baragay Sta. Ines, Tanay, Rizal, led to the conceptualization of a Four - year Development Plan to establsih some long - term solutions to aid the Dumagat community in its livelihood programs, education, technology and communication and its adaptation to the modern ways of practices. This study aims to seek answers to the preliminary questions set by the researcher:

1. What challenges were experienced by the Dumagat IP Community (Tanay, Rizal)?

2. What are the interventions / programs of the LGU of Tanay, Rizal to answer the pending challenges of its IP community?

3. What non-government interventions / programs were given to the Dumagat Community to solution their pending problems?

\section{Methodology}

A descriptive method of study, with a participatory action research (PAR) approach was utilized in the study. Collaborative actions from the Makati City Government (University of Makati) and the Municipality of Tanay was made and interventions from the non-government organizations linked with the Makati City Government and the Municipality of Tanay were sought to have concrete programs and activities for the IP community. The following instruments were used in the study: a. Data and Document Gathering and Analysis, b. Key Informants Interview and c. Observation and Experiential / Participatory study

\section{Results and Discussion}

The study adopted a framework that will lead to the establishment of a Four-year Development Plan. This plan will help the Dumagat Indigenous Community with sustainable livelihood programs, enhanced basic primary education, improved 
communication and technology and the adaptation of the people to the modern urban life that is gradually acculturating their place.

\section{Figure 1.}

The Theoretical Framework of the 4-year Development Plan for the IP Community of Brangay Sta. Ines, Tanay, Rizal

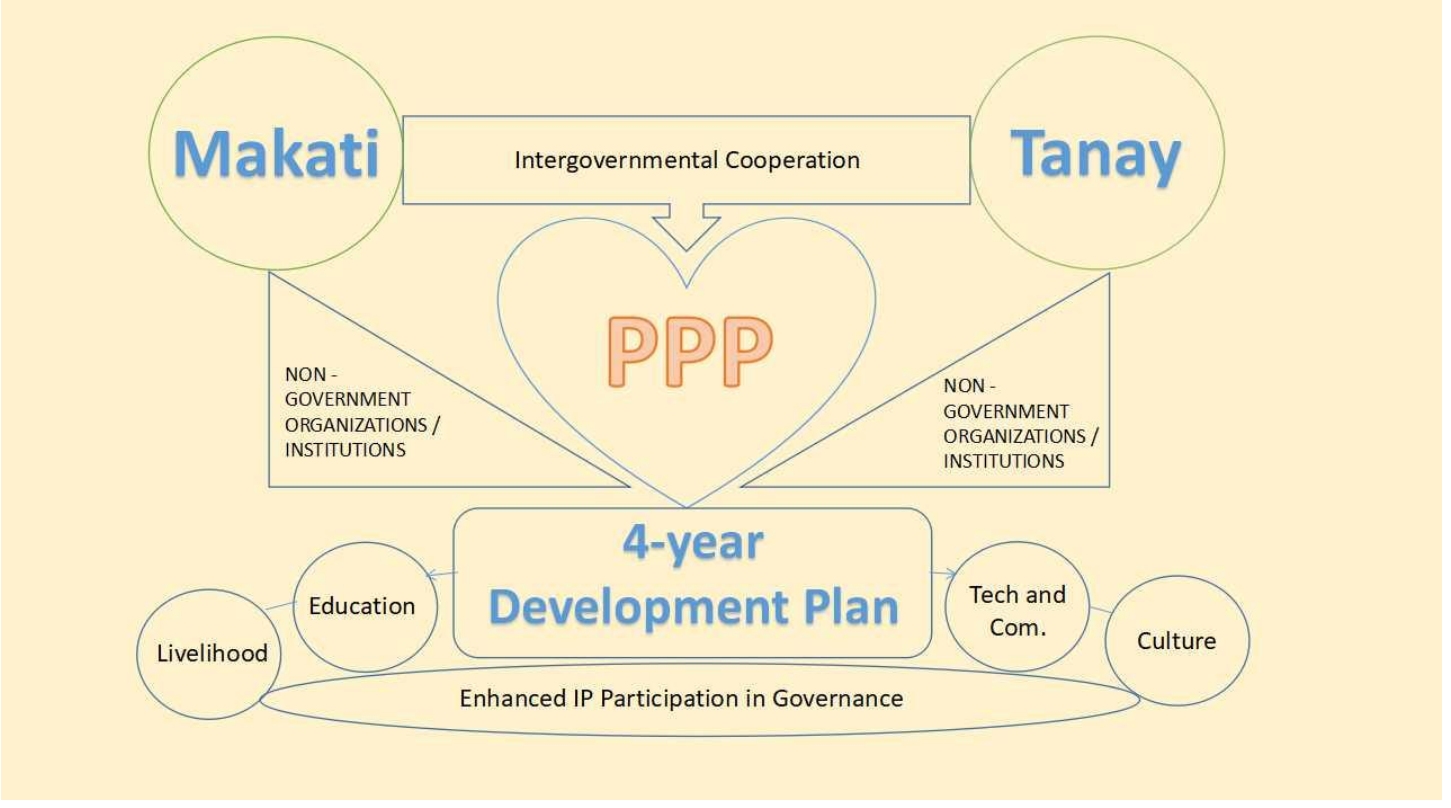

With the inter-governmental cooperation of the City of Makati (through The University of Makati) and the Municipality of Tanay, a collaboration between the two government brings a linkage to achieve the goal of uplifting the lives of the IP people in Tanay, Rizal, particularly the Dumagat ethnic group.

Public-private partnership between the government and its different non-government organization linkages will be the heart of the development plan. PPP involves the collaboration between a government agency and a private-sector company that can be used to finance, build, and operate projects, such as public transportation networks, parks, and convention centers. Financing a project through a public-private partnership can allow a project to be completed sooner or make it a possibility in the first place.

With the 4-year development plan, the study foresees an enhanced IP Participation in Governance. Developing Participatory Governance empowers the citizens to participate in public decision-making,for stronger government transparency, accountability and responsiveness, and for improved public policies and services. 
Participatory Governance will involve the practices of:

A. Public information - A first step towards participatory governance is helping citizens to have access to relevant information about government policies, decisions and actions. This category contains tools relating to advocating for freedom of information, supporting government transparency and facilitating the dissemination of public information.

B. Education and deliberation - citizens will be aware of their rights and responsibilities (civic education), and a variety of innovative methods for helping citizens collectively learn about and discuss issues of priority public concern.

C. Advocacy and citizen voice - This contains a number of tools for enhancing citizen advocacy, and helping citizens to publicly express their opinions and concerns.

D. Public dialogue - This describes a range of innovative approaches and tools for promoting more productive interactions and enhancing dialogue between multiple state and non-state actors.

E. Electoral transparency and accountability - This contribute to ensuring that elections are free and fair and help citizens make informed choices and hold politicians accountable for their electoral promises.

F. Policy and planning - The design and implementation of public policies and plans that respond effectively to citizens' priorities and needs are a key task of any government. These enables citizens and civil society organizations to contribute meaningfully to processes of public policy-making and planning, at both the local and national level.

G. Public budgets and expenditures - Transparent, accountable, effective and efficient public financial management is key to good governance. This will help citizens understand and influence decisions about the allocation of public resources, monitor public spending and hold governments accountable for the management of public financial resources.

H. Monitoring and evaluating public services - Services such as health care, education, water and sanitation and public transport are essential for citizens to survive and thrive. This offers innovative ways for citizens to monitor and evaluate the accessibility, quality and efficiency of public services - leading to improved services and better quality of life for all citizens. 
I. Public oversight - Many governments around the world are plagued by corruption, patronage and lack of accountability. This outlines a number of methods that citizens and civil society organizations can use to monitor and oversee public action and seek retribution for injustices or misdeeds.

With the different challenges that the Dumagat IP Community may experience, PPP is seen as a way to establish an enhanced IP participation in the government, through the collaborative governance of the Local Government of Makati and the Municipality of Tanay.

\section{Conclusion}

1. At this preliminary stage, setting the four - year development plan 2020 - 2024, different problems of the Dumagat IP Community in Barangay Sta. Ines, Tanay, Rizal had already been known. The following were:

a. Rights for the Ancestral Domain lands were not yet awarded and given to the Dumagat Community;

b. The Dumagat Community in Tanay, Rizal are mostly impoverished. These people are earning below the minimum wage (Php 400.00 in Rizal) that is required, as employment is hard for them and they rely on agricultural livelihood that may not be sufficient to gain decent living;

c. As technology may be gradually observed in the areas of Barangay Sta Ines, Tanay Rizal with cellphones and television, the energy supply for electricity may be limited. Roads are still under construction and the road to the different sitios are yet to be developed. Cell sites were not close to the area, so signal for cellular phones may still be weak.

d. Racial Discrimination is observed with the people living in the area of Tanay. Most of the IP Dumagat were to be seen as inferior in race by other people who are not "pure IP Dumagat" and the non - Dumagat group. Discrimination may be in form of"bullying," having more incentives and access to barangay aid and support, and the like. This may happen as the IP Dumagat may have developed the negative sense of inferiority complex within themselves. 
e. Though the National Government and the Provincial Government of Tanay, Rizal had given support and help to the IP Dumagat Community, lack of financial aid may still be visible with the facilities and technological change that may be brought and given to the IP community. The IP community still needs more accessible roads or path ways, more materials for good education, more aid for their basic needs like slippers, and good energy for electricity.

f. As more Dumagat strives to earn an academic degree, these people may leave their place after attaining a degree for a more profitable work in the city. This condition brings a "Brain Drain Phenomena."

2. The Municipal Government of Tanay, Rizal had been supportive of their IP Dumagat Community through the different programs and ordinances it was able to provide the IP group, such as scholarship programs are provided by the government, but only to qualified IP people.

The Municipal Government of Tanay Rizal is a first class Municipality with approx. 117,830 people. It was awarded with a Seal of Good Local Governance on September of 2019 for the different programs and activities that the Municipality had provided its people. However, the Municipality is also admitting that they my not able to answer all the needs of their IP community, as they are living in the far, hard to reach areas of the Municipality. Help from non-government organizations (NGO) are greatly welcomed by the Municipality to aid the Dumagat community.

3. The NGOs are seen as partners of the Municipality of Tanay in helping and providing the needs of the IP Dumagat Community. However, not all may be provided by these organizations and most programs of these NGO's are not sustainable.

\section{References}

Ecoben, Wenceslao B., Palparan, Alicia M. Society and Culture. Books Atpb Publishing. 2015.

Fast Facts: Indigenous Peoples in the Philippines. UNDP. Jul 24, 2013.

Panopio, Isabel S. Sociology: Focus on the Philippines. Ken, Incorporated. 1995.

San Juan, Wilfredo, Centeno, Ma. Luz. General Sociology. Books Atpb. Publishing. 2011. 
Valdeavilla, Ronica. A Guide to the Indigenous Tribes of the Philippines. April 25, 2018.

Will Kenton. Public-Private Partnerships. Mar 28, 2019. https://www.investopedia.com/terms/p/public-private-partnerships.asp 